\title{
A new Editor for Nutrafoods
}

Andrea Poli, Franca Marangoni

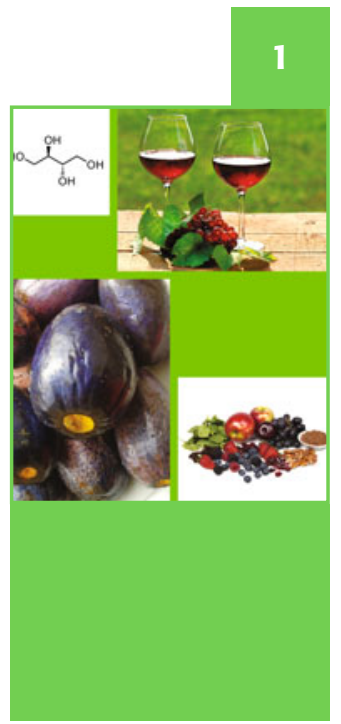

(C) Springer - CEC Editore 2015

This issue, which includes interesting papers such as a thorough and timely review on erythritol and two basic science papers that deal with nutritional antioxidants, is the last one we handle as Editors of Nutrafoods. We took over three years ago and we now leave a healthy journal, which receives many good-quality manuscripts. During this period, we tried to expand the aims and scopes of the journal, adding to its historical "botanicals" and "supplements" features an increasing number of diversified contributions and high-level reviews on strictly nutritional topics. We also expanded the reach of $\mathrm{Nu}$ trafoods, which now receives contributions from India and North Africa, in addition to the usual European and American authorship.
It is time to say farewell, but also to acknowledge and thank the many people who have contributed to Nutrafoods' success. First of all, we would like to thank the Editorial Board (namely, its sections editors) whose members acted as reviewers and solicitors of high-quality papers. We also would like to thank the numerous anonymous referees, who improved the scientific standard of Nutrafoods by providing rigorous evaluations.

Finally, we express our best wishes to the new Editor in Chief, Francesco Di Pierro, who will certainly further develop Nutrafoods thanks to his competence and dedication.

Arrivederci! 